of a tiger dispersing and settling far from its natal area on the Russian border provides support for the current plan to establish a North-east China/Russian Tiger Landscape.

Tianming Wang, Limin Feng, PU Mou and JiANPING Ge College of Life Sciences, Beijing Normal University, Beijing, China E-mailwangtianming@bnu.edu.cn

CHeNG LI Jilin Provincial Huangnihe Nature Reserve, Huangnihe Town, China

JAMES L.D. SMITH Department of Fisheries, Wildlife and Conservation Biology, University of Minnesota, St Paul, Minnesota, USA

\section{Conserving large mammals in partnership with private landowners in Assam, north-east India}

Conservationists are looking increasingly at lands outside protected areas to serve as secondary habitat or dispersal conduits for threatened species. In India, where protected areas are generally small, private landholdings can enhance the viability of wildlife populations. Research carried out by the Wildlife Conservation Society, India Program (WCS India) in north-east India has suggested that for conflictprone species such as the Asian elephant, private land does not serve as primary habitat but could facilitate connectivity. Building upon this finding, WCS India has initiated a connectivity project-predominantly in tea plantations, paddy fields and areas of human habitationbetween Kaziranga National Park and the hills of Karbi Anglong, Assam. The landscape is a unique floodplain ecosystem wherein animals move seasonally between inundated floodplains of Kaziranga and the higher reaches of Karbi Anglong.

In recognition of the potential conservation value of tea plantations, WCS India and Balipara Tract and Frontier Foundation have been working with six plantations, two of which are managed by Amalgamated Plantations Private Ltd, to foster their role as wildlife movement routes. Amalgamated Plantations Private Ltd Foundation, keen to form a model for conservation in tea plantations through adoption of wildlife-friendly management practices, supports the collaborative project initiated by WCS India and Balipara Tract and Frontier Foundation. Amalgamated Plantations Private Ltd Foundation has also tentatively set aside land in plantations between Kaziranga and Karbi Anglong for wildlife habitat and movement.

WCS India is conducting research to assess the conservation value of these lands for mammals. Initial surveys, during January-April 2015, with support from the Department of Science and Technology (Government of India), WCS New York and the Amalgamated Plantations Private Ltd Foundation, indicate that multiple species, including barking deer, leopards and elephants, use tea plantations. Meetings have been held with managers of all six plantations, and further investigations are underway to identify management practices that could sustain or enhance wildlife movement through tea plantations. Through these efforts, organizations involved in this programme aim to integrate scientific findings into decision-making in a manner that serves both wildlife conservation and human livelihood needs.

Divya VASUdEV and VARUN R. Goswami Wildlife Conservation Society, India Program, Bangalore, India

E-mail vasudev.divya@gmail.com

RoBin EASTMENT Balipara Tract and Frontier Foundation, Balipara, Assam, India

\section{Media workshops to improve reporting of human-wildlife interactions}

Interactions between people and wildlife are a common occurrence in many parts of India and much of South Asia. Large mammals that frequent human-inhabited areas are typically depicted in the media as fearsome and dangerous, increasing fear of wild animals and potentially instigating negative attitudes towards wildlife. Heightened antagonism towards wildlife also pressurizes park managers to take action when wildlife shares space with people. One common intervention is translocation of so-called problem leopards, which, as research conducted by the Wildlife Conservation Society, India Program (WCS India) has shown, can actually increase conflict with people near release sites.

In April 2015 WCS India held collaborative workshops to increase the sensitivity of media personnel in reporting human-wildlife interactions. This was part of a series of seven workshops conducted across multiple high-conflict states in India over the last 2 years, supported by the Rufford Foundation and WCS New York. Participants numbered more than 200, and included park managers involved in mitigating conflict, local conservation NGOs, and journalists from the English and local-language media. The workshops focused on the positive impacts that media reporting can have on the nature of human-wildlife interactions through shaping public perception of wildlife and influencing the way we deal with wild animals that occur in human-use lands. Workshop content included research findings on conflict-prone mammals from WCS India and other organizations (including the Nature Conservation Foundation and Centre for Conservation and Research); novel mitigation methods detailed by conservation practitioners; and a media perspective on human-wildlife conflict and how the media can reduce sensationalism and make people more aware of the complex nature of this issue. 